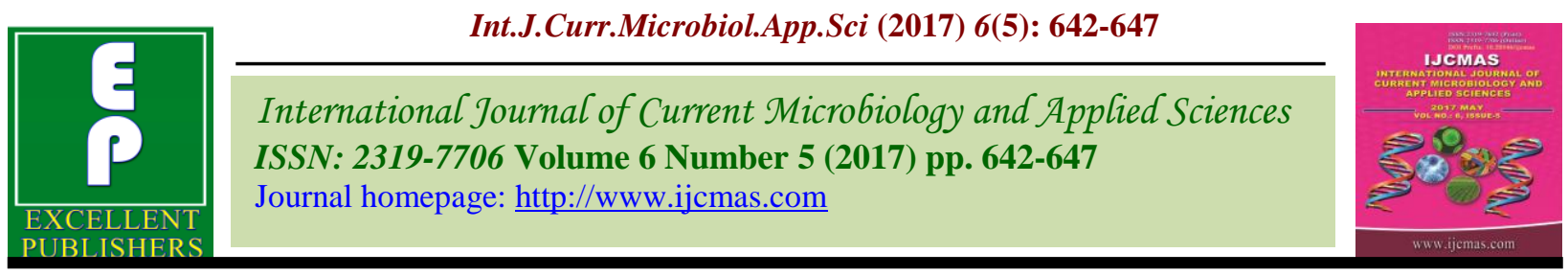

Original Research Article

https://doi.org/10.20546/ijcmas.2017.605.074

\title{
Study on Bacterial Spectrum of Organism Causing Diabetic Foot Ulcers with its Antibiogram in Dr. B.R. Ambedkar Medical College, Bangalore, India
}

\author{
S.M. Suhani*, Saroj Golia and Jyoti \\ Department of microbiology at DR.B R Ambedkar Medical College and Hospital, \\ Bangalore, India \\ *Corresponding author
}

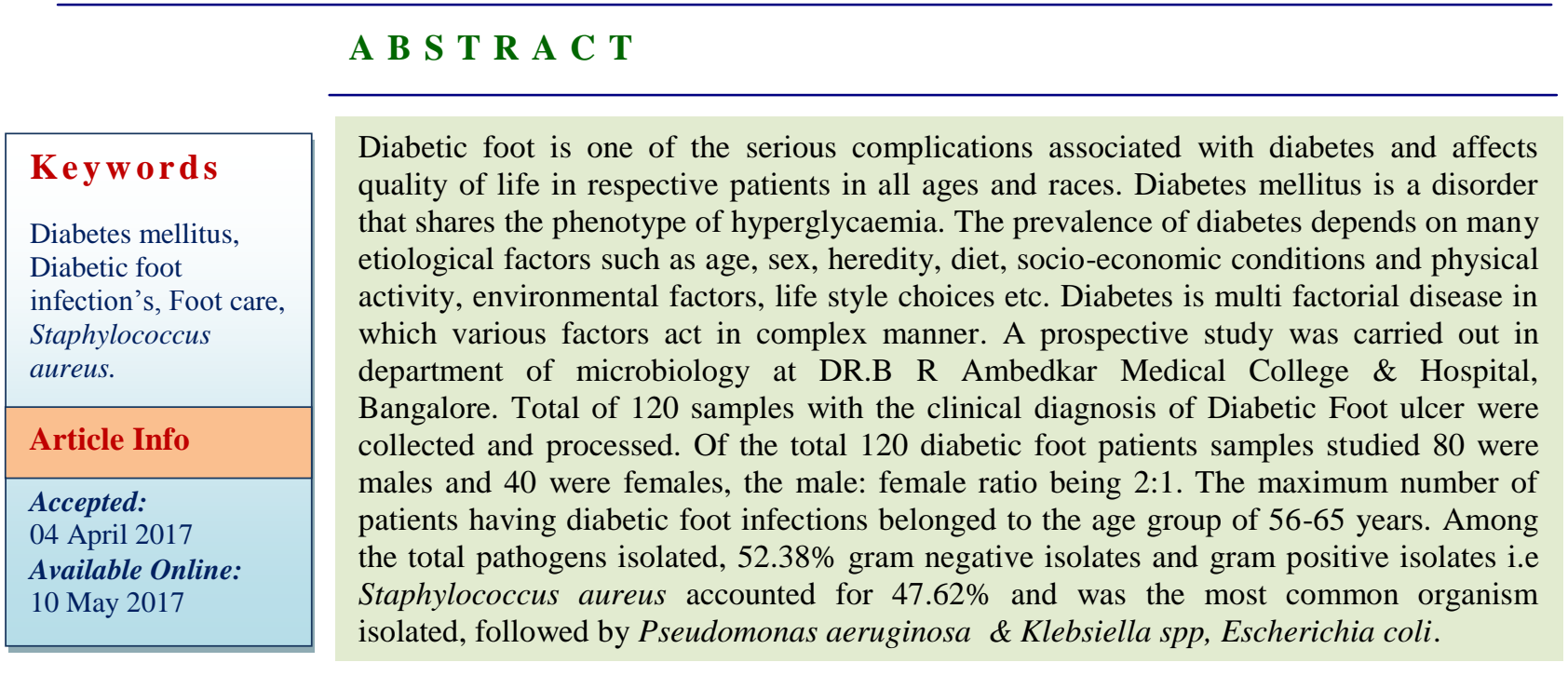

\section{Introduction}

Diabetic foot is one of the serious complications associated with diabetes and affects quality of life in respective patients in all ages and races. Diabetes mellitus is a disorder that shares the phenotype of hyperglycaemia. The prevalence of diabetes depends on many aetiological factors such as age, sex, heredity, diet, socio-economic conditions and physical activity, environmental factors, life style choices etc. Diabetes is multi factorial disease in which various factors act in complex manner (Kasper Dennis et al., 2005).

Neuropathy, peripheral arterial disease, and pressure overload make the sufferers prone to ulcer. Among persons with diabetes mellitus, the risk of developing a foot ulcer is estimated to be $15 \%$. Based on recent studies, the annual population based incidence ranges from $1.0 \%$ to $4.1 \%$ and the prevalence range from $4 \%$ to $10 \%$, suggesting the life time incidence as high as 25\% (Singh et al., 2005).

Patients with diabetes lose the protective sensations for temperature and pain, impairing awareness of trauma such as abrasions, blistering, or penetrating foreign body (Lipsky et al., 2004). Motor neuropathy can result in foot deformities that contribute to local pressure from footwear, making skin ulceration even more likely. Once the skin is 
broken (typically on the plantar surface), the underlying tissues are exposed to colonization by pathogenic organisms. The resulting wound infection may begin superficially, but with delay in treatment and impaired body defense mechanisms caused by neutrophil dysfunction and vascular insufficiency, it can spread to the contiguous subcutaneous tissues and to even deeper structures (Abdulrazak et al., 2005). So the present study is designed to isolate and identify bacterial causes in diabetic patients and assess their susceptibility to antibiotics.

\section{Materials and Methods}

A prospective study was carried out in department of microbiology at DR.B R Ambedkar Medical College \& Hospital, Bangalore, India.

Swabs obtained from diabetic foot ulcers cases during one year period from Dec 2015Jan2017 were collected \& processed. Patients details including age, sex, registration no, unit, occupation, history of trauma, habits of bare foot walking, alcohol, smoking, socioeconomic status, past history of the disease and duration of the disease, treatment taken and any complications, existing comorbidities.

E.g. Hypertension, Tuberculosis, Malnutrition, Anemia, Peripheral vascular disease were obtained

Collection of specimen: Discharge from margins and edges of ulcer were collected with help of two sterile swabs, one of which was used for gram stain and other for culture before antiseptic dressing was applied. Then swabs were immediately transported to the laboratory for culture.

Laboratory Procedures: All samples were subjected to conventional culture methods.
All the samples were subjected to Gram's staining for microscopic examination and culture as per standard guidelines. The exudates were cultured on Blood agar and MacConkey agar. The specific identification of bacterial pathogens was based on microscopic morphology, staining characteristics, culture and biochemical properties using standard laboratory criteria. Antimicrobial sensitivity of the bacterial isolates was done on Mueller Hinton agar using Kirby Bauer disc diffusion method as recommended by Clinical and Laboratory Standards Institute (CLSI).

\section{Results and Discussion}

Total of 120 samples with the clinical diagnosis of Diabetic Foot ulcer were collected and processed. Out of 120 specimens, 105 (87.5\%) specimens showed bacterial growth, while $15(12.5 \%)$ specimens did not show any growth.

Of the total 120 diabetic foot patients samples studied 80 were males and 40 were females, the male: female ratio being 2:1.Age group ranged from 28 years to 70 years with an average of 55 years. The maximum number of patients having diabetic foot infections belonged to the age group of 56-65 years.

Table 2 Illustrates the bacterial isolates which shows $52.38 \%$ gram negative isolates and gram positive isolates i.e Staphylococcus aureus accounted for $47.62 \%$ and was the most common organism isolated, followed by Pseudomonas aeruginosa \& Klebsiella spp, Escherichia coli.

The Result of the test for susceptibility to the commonly used antibiotics are shown in Table no. 3, 4and 5. Antibiotic sensitivity pattern of staphylococcus aureus showed that Cefoxitin resistance i.e., Methicillin resistant S.aureus (MRSA) was 54\%, combination of 
Amoxycillin/Clavulanic acid showed $70 \%$ sensitivity while Gentamicin and Cefuroxime showed $65 \%$ and $50 \%$ sensitivity respectively. Erythromycin and Azithromycin showed $75 \%$ resistant pattern while Cefadroxil showed 55\% resistance. Almost all isolates of Pseudomonas aeruginosa were sensitive to Piperacillin + Tazobactam, Cefipime and Imepenem, 80\%, 76\%, 100\% respectively.

Foot ulceration is the most severe complication affecting diabetic patients which is not confined to certain superficial underlying subcutaneous tissue. Diabetic foot ulceration (DFU) arises from uncontrolled diabetes and incomplete health self-care (Mendes et al., 2012; American Diabetes Association, 2011).

This study investigates clinical and microbiological findings of DFU in patients. The majority of the patients with DFU were male and older than 50 years, consistent with other reported studies such as llanes et al., (2001) which shows maximum age group above 57 years. This may be due to factors such as the differences in life styles and professional activities and jobs, causing the feet to tolerate more pressure.

In the present study, 105 organisms were isolated from 120 patients and S.aureus accounts for the major organism isolated. The observations are similar with Chincholikar (2002) while differ significantly from Ekta et al., (2008) in which the major organism are GNB which again indicated the role of geographical variations in microbial etiology. Staphylococcus aureus was predominantly isolated organism $(47.62 \%)$ followed by Pseudomonas aeruginosa (23.81\%), Klebsiella (14.29\%) and E coli (4.76\%).

Other organisms like Proteus mirabilis, P.vulgaris, Citrobacter spp and Acinetobacter spp were also isolated. Almost similar results were obtained by Vvimalin Hena et al., (2010) \& Murtada Jeber et al., (2013). In our study, Methicillin resistance was seen in 54\% of the $S$. aureus which is also in concordance with findings by Gadepalli et al., Ekta et al., (2008) and Chincholikar (2002) in which MRSA was seen in 56\%, 55.50\% and $55.56 \%$ respectively. Staphylococcus spp., being the predominant organism isolated showed linezolid and teicoplanin to be the most effective antibiotics with $100 \%$ sensitivity and low resistance was seen to amoxy-clav $(40 \%, \mathrm{n}=50) \&$ gentamicin $(44 \%, \mathrm{n}=50)$ but a high resistance was exhibited to other antibiotics. Other studies have shown different susceptibility antibiotic patterns and approximately in most vancomycin and linezolid have shown good activity against the strains. The antibiotic sensitivity pattern of Pseudomonas was approximately similar to study by Ekta et al., (2008). Most of the isolates were sensitive to almost all drugs used with Piperacilin/Tazobactam (80\%:n=25),being most sensitive $(80 \%, \mathrm{n}=25)$,followed by Ceftazidime $(72 \%, \mathrm{n}=25), \quad$ Cefepime $\quad(76 \%, \mathrm{n}=25)$, Amikacin (64\%, $\mathrm{n}=25)$ \& low level of resistance seen to Flouroquinolones.

Table.1 Pattern of isolation of microbial growth from Diabetic Foot Ulcer

\begin{tabular}{|l|l|}
\hline Total Patients examined & 120 \\
\hline Patients with microbial growth n (\%) & $105(87.5 \%)$ \\
\hline No growth n (\%) & $15(12.5 \%)$ \\
\hline Gram Positive Isolates & $47.62 \%$ \\
\hline Gram Negative Isolates & $52.38 \%$ \\
\hline
\end{tabular}


Table.2 Bacterial Pathogens isolated from 105 Culture Positive Diabetic Foot Ulcers

\begin{tabular}{|l|l|l|}
\hline Organism & Isolates & $(\mathbf{n = 1 0 5}) \mathbf{( \% )}$ \\
\hline Staphylococcus aureus & 50 & $47.62 \%$ \\
\hline Pseudomonas aeruginosa & 25 & $23.81 \%$ \\
\hline Klebsiella spp & 15 & $14.29 \%$ \\
\hline Escherischia coli & 5 & $4.76 \%$ \\
\hline Proteus mirabilis & 3 & $2.86 \%$ \\
\hline Proteus vulgaris & 3 & $2.86 \%$ \\
\hline Citrobacter spp. & 2 & $1.90 \%$ \\
\hline Acinetobactor spp & 2 & $1.90 \%$ \\
\hline
\end{tabular}

Table.3 Antibiogram of Staphylococcal isolates from diabetic foot ulcers $(n=50)$

\begin{tabular}{|l|l|l|l|l|}
\cline { 2 - 6 } \multicolumn{1}{c|}{} & \multicolumn{2}{l}{$(\mathrm{n}=50)$} & $\mathrm{R}$ & $\%$ \\
\hline Anti microbial agent & $\mathrm{S}$ & $\%$ & 20 & $40.00 \%$ \\
\hline Amoxycillin/Clav.acid & 30 & $60.00 \%$ & 35 & $70.00 \%$ \\
\hline Azithromycin & 15 & $30.00 \%$ & 38 & $76.00 \%$ \\
\hline Erythromycin & 12 & $24.00 \%$ & 25 & $50.00 \%$ \\
\hline Cefuroxime & 25 & $50.00 \%$ & 23 & $46.00 \%$ \\
\hline Cefoxitin sensitive & 27 & $54.00 \%$ & 22 & $44.00 \%$ \\
\hline Cefadroxil & 28 & $56.00 \%$ & 22 & $44.00 \%$ \\
\hline Gentamicin & 28 & $56.00 \%$ & 5 & $10.00 \%$ \\
\hline Linezolid & 45 & $90.00 \%$ & - & - \\
\hline Teicoplanin & 50 & $100.00 \%$ & \multicolumn{2}{|l|}{} \\
\hline
\end{tabular}

Table.4 Antimicrobial sensitivity of isolates of Pseudomonas aeruginosa $(n=25)$

\begin{tabular}{|l|l|l|l|l|}
\cline { 2 - 5 } \multicolumn{1}{c|}{} & \multicolumn{2}{c}{$\mathrm{n}=25$} \\
\hline Anti microbial agent & $\mathrm{S}$ & $\%$ & $\mathrm{R}$ & $\%$ \\
\hline Piperacilin/Tazobactam & 20 & $80.00 \%$ & 5 & $20.00 \%$ \\
\hline Ceftazidime & 18 & $72.00 \%$ & 7 & $28.00 \%$ \\
\hline Cefepime & 19 & $76.00 \%$ & 6 & $24.00 \%$ \\
\hline Amikacin & 16 & $64.00 \%$ & 9 & $36.00 \%$ \\
\hline Gentamicin & 17 & $68.00 \%$ & 8 & $32.00 \%$ \\
\hline Ciprofloxacin & 10 & $40.00 \%$ & 15 & $60.00 \%$ \\
\hline Levofloxacin & 12 & $48.00 \%$ & 13 & $52.00 \%$ \\
\hline Doripenem & 24 & $96.00 \%$ & 1 & $4.00 \%$ \\
\hline Imepenem & 25 & $100.00 \%$ & 0 & $0.00 \%$ \\
\hline
\end{tabular}


Table.5 Antimicrobial susceptibility pattern of gram negative bacteria except Pseudomonas $(\mathrm{n}=105)$

\begin{tabular}{|l|l|l|l|l|l|l|}
\cline { 2 - 7 } \multicolumn{2}{l|}{} & $\mathrm{n}=105$ & \multicolumn{3}{l|}{ Klebsiella } \\
Anti microbial agent & $\begin{array}{l}\text { Escherischia } \\
\text { soli }\end{array}$ & $\begin{array}{l}\text { Proteus } \\
\text { mirabilis }\end{array}$ & $\begin{array}{l}\text { Proteus } \\
\text { vulgaris }\end{array}$ & $\begin{array}{l}\text { Citrobacter } \\
\text { spp. }\end{array}$ & $\begin{array}{l}\text { Acinetobacter } \\
\text { spp }\end{array}$ \\
\hline Imipenem & $86.67 \%$ & $80.00 \%$ & $100.00 \%$ & $100.00 \%$ & $100.00 \%$ & $100.00 \%$ \\
\hline Amikacin & $66.67 \%$ & $60.00 \%$ & $66.67 \%$ & $33.33 \%$ & $50.00 \%$ & $50.00 \%$ \\
\hline Gentamicin & $73.33 \%$ & $60.00 \%$ & $66.67 \%$ & $33.33 \%$ & $100.00 \%$ & $50.00 \%$ \\
\hline Ciprofloxacin & $46.67 \%$ & $40.00 \%$ & $33.33 \%$ & $66.67 \%$ & $50.00 \%$ & $0.00 \%$ \\
\hline Levofloxacin & $40.00 \%$ & $40.00 \%$ & $33.33 \%$ & $66.67 \%$ & $100.00 \%$ & $0.00 \%$ \\
\hline Ofloxacin & $40.00 \%$ & $60.00 \%$ & $33.33 \%$ & $66.67 \%$ & $100.00 \%$ & $50.00 \%$ \\
\hline Cefotaxime & $33.33 \%$ & $40.00 \%$ & $66.67 \%$ & $33.33 \%$ & $50.00 \%$ & $50.00 \%$ \\
\hline Ceftriaxone & $46.67 \%$ & $60.00 \%$ & $66.67 \%$ & $33.33 \%$ & $50.00 \%$ & $100.00 \%$ \\
\hline Cefipime & $66.67 \%$ & $80.00 \%$ & $66.67 \%$ & $66.67 \%$ & $100.00 \%$ & $100.00 \%$ \\
\hline Co-trimoxazole & $40.00 \%$ & $40.00 \%$ & $100.00 \%$ & $66.67 \%$ & $100.00 \%$ & $50.00 \%$ \\
\hline $\begin{array}{l}\text { Ampicillin/ } \\
\text { Sulbactam }\end{array}$ & & & & & & \\
\hline
\end{tabular}

All isolates were found $100 \%$ sensitivity to Imipenam. In present study, Klebsiella and $E$. coli were mostsensitive to combination like Ampicillin + Sulbactam, Gentamicin, Cefipime, Imepenem and these organisms were resistant to other Cephalosporins, Cotrimoxazole and Flouroquinolone. Similar results were found by Ekta et al., (2008). The antibiotic resistance shown in the present study may be due to such factors including hospitalization, recent use of broad-spectrum antibiotics, history of surgery and chronic wounds, irrational use of antibiotics, and the transfer of resistance genes by transport means. To alleviate this situation and also reduce the rate of amputation, clinicians should prescribe antibiotics rationally, timely, and sufficiently and there should be periodic supervisions on the drug consumption by the respective organizations (Farshad et al., 2011).

It can be concluded that culture specimens for correct management of the DFI and knowledge of the susceptibility of antimicrobial drugs are essential for the choice of appropriate antibiotics with maximum efficacy. Diabetic foot infections are polymicrobial in nature

Organisms in mixed infections showed multidrug resistance as compared to single isolated strain.

These multidrug resistant organisms are frequently resistant to many classes of antibiotics so it is necessary for the clinician to be completely aware of the prevalence rate of multidrug resistant organisms and their management strategies. So this study will help the clicians to choose appropriate antibiotic or combination of antibiotics forthe treatment of Diabetic Foot Ulcer.

\section{References}

Abdulrazak, A., Bitar, Z.I., Al-Shamali, A.A. and Mobasher, L.A. 2005. Bacteriological study of diabetic foot infections. J. Diab. Compl., 19(3): 139- 
141

American Diabetes Association. 2011. Standards of medical care in diabetes, Diabetes $\quad$ Care, 34 (supplement 1): S11-S61. doi: 10.2337/dc11-s011.

Bansal Ekta, Garg Ashish, Bhatia Sanjeev, Attri, A.K., Chander Jagdish. 2008. "Spectrum of microbial flora in diabetic foot ulcers" Vol. 51, issue 2, Page 204208.

Chincholokar, D.A., Pal, R.B. 2002. Study of fungal and bacteriologicalinfections of the diabetic foot. Indian J. Pathol. Microbial., 45: 15-72.

Farshad, S., Anvarinejad, M., Tavana, A.M., et al. 2011. Molecular epidemiology of Escherichia coli strains isolated from children with community acquired urinary tract infections. African $J$. Microbiol. Res., 5(26): 4476-4483. doi: 10.5897/ajmr 11.285.

Gadepalli Ravisekhar, Kapil Arti, Dhawan Benu, Ammini A. C., Sreenivas Vishnubhatla, Chaudhary Rama. "A Clinical microbiological study of Diabetic foot ulcers in an Indian tertiary care hospital" Volume 29, Page no. 1727-173.

Hefni, A.A.H., Ibrahim A.M.R., Attia, K.M., et al. 2013. Bacteriological study of diabetic foot infection in Egypt. J. Arab Soc. Med. Res., 8: 26-32.

Kasper Dennis, L., Fauci Anthony, S., Longo, Dan, L., Braunwald Eugene, Hauserm Stephen, L., Jameson, J., Larry. 2005. "Harrison's Principles of internal Medicine", Edition $16^{\text {th }}$, Volume II,
Page No. 2152-2179.

Lea Renina, I., Llanes, M.D., Adrian, C., Pana, Rochella cauton Valera. 2001. Clinical microbiological profile and outcome of diabeticpatients with foot ulcers admitted at the Quirino Memorial Medical Centre.

Lipsky, B.A., Berendt, A. and Deery, H.G. 2004. Diagnosis and treatment of diabetic foot infections. Clin. Infect. Dis., 39(7): 885-910.

Mehta, V.J., Kikani, K.M., Mehta, S.J. 2003. Microbiological profile of diabetic foot ulcers and its antibiotic susceptibility pattern in a teaching hospital, Gujarat. Int. J. Basic \& Clin. Pharmacol., 3(1): 92-95. doi: 10.5455/2319-2003.ijbcp20140209.

Mendes, J., Neves, J. 2012. Diabetic foot infections: current diagnosis and treatment. J. Diabetic Foot Complications, 4(2): 26-45.

Murtada, A., Jeber, Eiman, A. 2013. Saeed. "Isolation and Identification of bacterial causes from diabetic foot ulcers". Tikrit J. Pure Sci., 18(3).

Performance Standards for Antimicrobial Susceptibility Testing, M100 - S26 $\left(26^{\text {th }}\right.$ edition), CLSI - 2016.

Singh Nalin, Armstrong David, G., Lipsky Benjamin, A. 2005. J. American Med. Assoc., Edition 2005, 293, page No. 217-228.

Vimalin Hena, J., Lali Growther. 2010. "Studies on bacterial infections of diabetic foot ulcer" Afr. J. Cln. Exper. Microbiol., 11(3): 146-149.

\section{How to cite this article:}

Suhani, S.M., Saroj Golia and Jyoti. 2017. Study on bacterial spectrum of organism causing diabetic foot ulcers with its antibiogram in Dr. B.R. Ambedkar Medical College, Bangalore, India. Int.J.Curr.Microbiol.App.Sci. 6(5): 642-647.

doi: https://doi.org/10.20546/ijcmas.2017.605.074 